\title{
Mechanism of Corrosion Inhibition with Bismuth Compounds for Iron, Nickel and Zinc in Acid Solutions
}

\author{
Masaru IHARA, Hiroshi NISHIHARA and Kunitsugu ARAMAKI*
}

Received January 16, 1991 ; Accepted March 12, 1992

\begin{abstract}
Formation of a highly corrosion-protective and persistent film on iron with bismuth (II) chloride in acid solutions has been reported in our previous paper. In order to investigate the inhibition mechanism of metallic corrosion with bismuth (II) compounds in acid solutions, inhibition efficiencies of the compounds for iron, nickel, and zinc in $1 \mathrm{~N} \mathrm{HClO} 4$ were determined by polarization measurements. X-ray photoelectron spectra showed that the protective films formed on the metal were composed of an outer layer comprising metallic $\left(\mathrm{Fe}^{2+}, \mathrm{Ni}^{2+}\right.$ or $\left.\mathrm{Zn}^{2+}\right)$ and $\mathrm{Bi}^{3+}$ oxides and an inner layer consisting of metallic bismuth. Dramatic inhibition effects of the inhibitors are attributed to the coating of metallic bismuth with a high hydrogen-overpotential on the almost whole area of metal substrate and to the adsorption of an inhibitive anion on the faintly exposed area of metal substrate covered with the outer layer.
\end{abstract}

\section{I NTRODUCTION}

A series of investigations ${ }^{1-4}$ ) have dealt with inhibition effects of inhibitors including typical elements of high atomic numbers on metallic corrosion. A new type of corrosion inhibitors, organoantimony ${ }^{1-3)}$ and organobismuth ${ }^{4}$ compounds have been examined for iron and nickel in acid solutions. They form highly persistent and protective films on the iron surface in acid solutions, resulting in high inhibition efficiencies even at low concentrations. The films thus formed on the iron surface consist of multiple layers: an outer layer composed of $F(I I)$ and $\mathrm{Sb}(\mathbb{I})$ or $\mathrm{Bi}(\mathbb{I})$ oxides and an inner

Department of Chemistry, Faculty of Science and Technology, Keio University (3-14-1 Hiyoshi, Kohoku-ku, Yokohama 223) Key Words: Metallic corrosion inhibitor, Bismuth(II) compounds, Protective film, XPS, EPMA. layer of metallic antimony or bismuth.

The inhibition efficiency of $B i(\mathbb{I})$ chloride has been measured for iron corrosion in $1 \mathrm{~N} \mathrm{HClO}_{4}$, iN HCl, and $1 \mathrm{~N} \mathrm{H}_{2} \mathrm{SO}_{4}{ }^{5}$. This compound is an excellent inhibitor by forming a protective film against iron corrosion. The $\mathrm{film}$, comprising an outer layer composed of oxides and an inner one of metallic bismuth, is remarkably persistent against corrosion in an acid solution without the inhibitor. The high inhibition efficiency is mainly attributed to the outer and inner layer and the marked persistence to the inner layer. Bismuth (I) chloride surpass organoantimony and organobismuth compounds in stability against oxidation with oxygen and are less toxic by far than antimony compounds.

This work was undertaken to investigate the mechanism of corrosion inhibition for iron, nickel, and $z i n c$ in an acid solution with bismuth(I) compounds by polarization measurements and cyclic voltammetry. The 
protective films formed on the metals with the bismuth compounds were analyzed by $x-$ ray photoelectron spectroscopy (XPS) and electron-probe microanalys is (EPMA).

\section{EXPER IMENTAI.}

Inhibitors used in this study were bismuth(II) chloride, iodide, sulfate, and oxide. An acid solution, $1 \mathrm{~N} \mathrm{HClO}_{4}$ was prepared by diluting an analytical reagent with redistilled water and deaerated by passing a nitrogen gas through it.

Disks of $99.9 \% \mathrm{Fe}, 99.99 \% \mathrm{Ni}$, and $99.99 \%$ Zn (10.0 ram diam) were fixed at the end of a glass tube holder with a thermo-shrinkable Tefion tube and epoxy adhesive. A rod of $99.99999 \% \mathrm{Bi}(8.0 \mathrm{~mm} \mathrm{diam})$ was embedded in a Teflon holder. The surface of these metallic electrodes was prepared in the same manner as has been described i). The electrodes except the bismuth one were discarded following each run of measurements because a layer of bismuth deposit could not be removed completely from the electrode surface by abrasion with emery papers.

Polarization curves of iron, nickel, zinc and bismuth electrodes were potentiostatically measured in deaerated $1 \mathrm{~N} \mathrm{HClO}_{4}$ with and without the inhibitor at $30^{\circ} \mathrm{C}$. The potential was referred to a saturated calomel electrode(SCE). Cyclic voltammetry for the bismuth electrode was carried out in $1 \mathrm{~N} \mathrm{HClO}_{4}$ containing $1 \times 10^{-4} \mathrm{M}$ (mol $\mathrm{dm}^{-3}$ ) of $\mathrm{BiCl}_{3}$ at the scan rate of $0.1 \mathrm{~V} \mathrm{~s}^{-1}$ under a nitrogen atmosphere.

$X$-ray photoelectron spectra of the protective films formed on the nickel and zinc surfaces were measured using JEOL90SX spectrometer with $M g K_{\alpha}$ radiation as an $X$-ray source. The nickel and $z$ inc disks were previously treated with bismuth chloride at $1 \times 10^{-4} \mathrm{M}$ in a deaerated $\mathrm{IN}$ $\mathrm{HClO}_{4}$ solution at $30^{\circ} \mathrm{C}$ for $1 \mathrm{~h}$. The treated disks were rinsed with water, dried under vacuum overnight, mounted on a standard sample probe and placed in a sample chamber of the spectrometer. All manipulations after prior treatment were carried out under a nitrogen atmosphere.

The binding energies for components of interests, Ni (2p), $\mathrm{Zn}(2 \mathrm{p}), \mathrm{O}(1 \mathrm{~s}), \mathrm{Cl}(2 \mathrm{p})$, and $\mathrm{Bi}(4 \mathrm{f})$ were referred to the binding energy of $\mathrm{C}\left(1 \mathrm{~s}_{1 / 2}\right)$ at $284.6 \mathrm{eV}$. In order to observe depth profiles of components in the protective films, an ion bombardment of the films was carried out with an $\mathrm{Ar}^{+}$ gun. The sputtering time of 1 min corresponds to about $50 \mathrm{~nm}$ in depth.

The iron disks treated with bismuth chloride and sulfate at $1 \times 10^{-4} \mathrm{M}$ in deaerated $1 \mathrm{~N} \mathrm{HClO}_{4}$ at $30^{\circ} \mathrm{C}$ for $1 \mathrm{~h}$ were rinsed with water under a nitrogen atmosphere and dried under vacuum overnight. Line analyses of elements, Fe, Bi, Cl, and $\mathrm{S}$ at the surfaces of the iron disks were performed using a Shimadzu EPMA-8703 analyzer after a SEM image observation.

\section{RESULTS AND}

\section{I SCUSSION}

3.1 Inhibition effects of $\mathrm{BiCl}_{3}$ on corrosion of iron, nickel and $z$ inc in $1 \mathrm{~N} \mathrm{HClO}_{4}$.

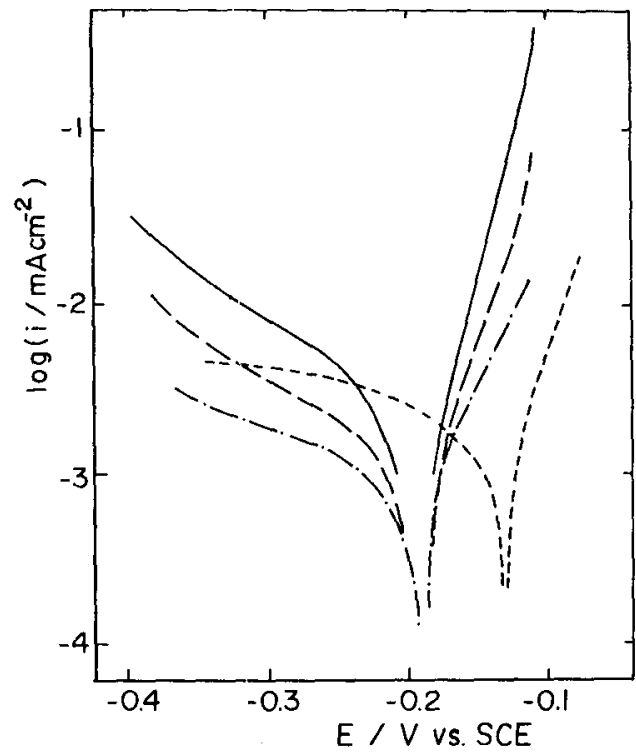

Fig. 1 Polarization curves (potential E and current density i) of nickel in $1 \mathrm{~N}$ $\mathrm{HClO}{ }_{4}$ without (—) and with $\mathrm{BiCl}_{3}$ at $1 \times 10^{-6} \mathrm{M}(--), 1 \times 10^{-5} \mathrm{M}(-\cdots)$, and $1 \times 10^{-4} M(---)$. 
Polarization curves of the nickel and zinc electrode in $1 \mathrm{~N} \quad \mathrm{HClO}_{4}$ with and without $\mathrm{BiCl}_{3}$ at various concentrations are shown in Figs. 1 and 2, respectively. Bismuth chloride suppressed both the anodic and cathodic reactions of nickel and zinc corrosion as well as iron corrosion.

The corrosion potential $E_{c o r}$ and the corrosion current density were obtained by extrapolating the anodic and cathodic Tafel lines. The values of $E_{c o r}$ for the nickel and zinc electrodes inhibited with $\mathrm{BiCl}_{3}$ at concentrations between $1 \times 10^{-8}$ and $1 \times 10^{-4} \mathrm{M}$ shifted toward a noble potential at most by $30 \mathrm{mV}$ from the value of the uninhibited electrode. Only an exception was $E_{c o r}$ of the nickel electrode inhibited with $1 \times 10^{-4} \mathrm{M}$ of $\mathrm{BiCl}_{3}$, shifting by $120 \mathrm{mV}$ from the value of the uninhibited one.

The inhibition efficiency $I$ was obtained by

$$
I / \%=100\left(1-i c o r / i c o r{ }^{0}\right)
$$

where $i_{c o r}$ and $i_{c o r}{ }^{0}$ represent the corrosion current densities of the inhibited

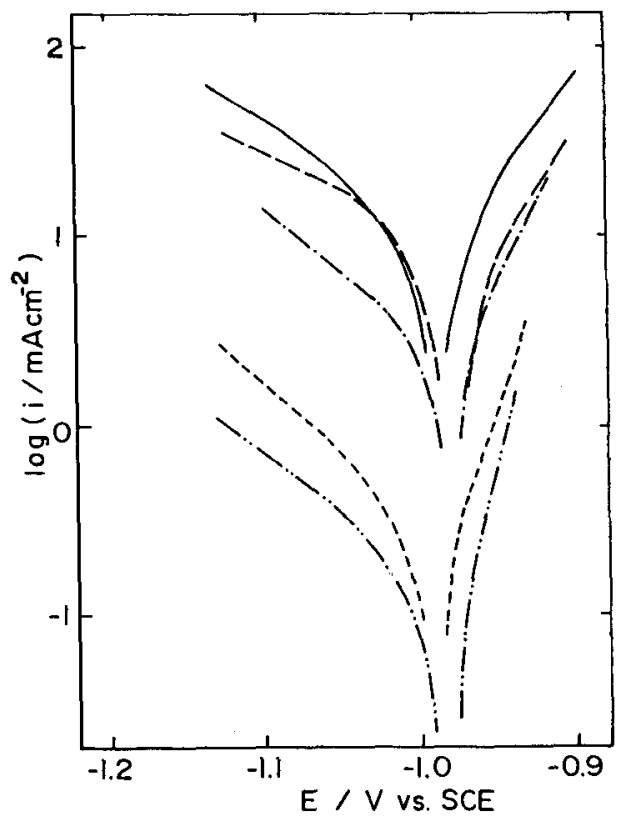

Fig. 2 Polarization curves of zinc in IN $\mathrm{HClO}_{4}$ without (-) and with $\mathrm{BiCl}_{3}$ at $1 \times 10^{-9} \mathrm{M}(--), 1 \times 10^{-3} \mathrm{M}(-\cdot-), 1 \times 10^{-6} \mathrm{M}$ $(---)$, and $1 \times 10^{-4} \mathrm{M}(-\cdots--)$.

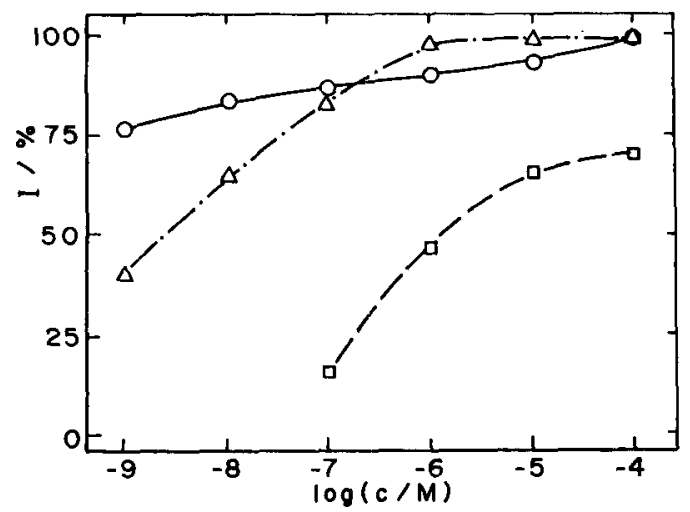

Fig. 3 Inhibition efficiency $\mathrm{I}$ of $\mathrm{BiCl}_{3}$ at various concentrations $c$ in $1 \mathrm{~N} \mathrm{HClO}_{4}$ for iron $(O)$, nickel $(\square)$, and zinc $(\Delta)$.

and uninhibited electrode, respectively. Figure 3 shows inhibition efficiencies of $\mathrm{BiCl}_{3}$ for aickel and $\mathrm{zinc}$ in $1 \mathrm{~N} \mathrm{HClO}_{4}$, together with the values for the iron electrode previously reported ${ }^{5)}$. Bismuth chloride was an efficient inhibitor for zinc, of which $I$ values (more than $98 \%$ at $\left.1 \times 10^{-6} \mathrm{M}\right)$ are comparable with those for iron. This inhibitor was, however, less effective on nickel corrosion in $1 \mathrm{~N} \mathrm{HClO}_{4}$, indicating about $70 \%$ of $\mathrm{I}$ at $1 \times 10^{-4} \mathrm{M}$.

3.2 Structures of protective films on iron, nickel, and zinc electrodes.

$X$-ray photoelectron spectra of components, (a) nickel, (b) oxygen, (c) chlorine, and (d) bismuth for the protective film formed on the nickel electrode and their depth profiles are shown in Fig. 4. At the outermost part of the film (sputtering time $t_{s}=0 \mathrm{~s}$ ), peaks of $\mathrm{Ni}\left(2 \mathrm{p}_{3 / 2}\right), \quad \mathrm{O}\left(1 \mathrm{~s}_{1 / 2}\right), \quad$ and $\mathrm{Bi}\left(4 \mathrm{f}_{7 / 2}\right)$ appeared at $856.5,532.5$, and $156.6 \mathrm{eV}$ of the binding energy, indicating the presence of $\mathrm{Ni}^{2+}, \mathrm{O}^{2-}$ combined with $\mathrm{H}^{+}$, and $\mathrm{Bi}^{3+}$, respectively. Intensities of the $\mathrm{Ni}^{2+}$ and $\mathrm{Bi}^{3+}$ peak increased and then decreased with an increase in $t_{s}$. A peak of zero-valent nickel appeared at $852.5 \mathrm{eV}$ inside the film and the intensity increased with $t_{s}$. A peak of $0\left(1 s_{1 / 2}\right)$ emerged at $530.1 \mathrm{eV}$, being indicative of the presence of $\mathrm{O}^{2-}$ in the film. Chlo- 


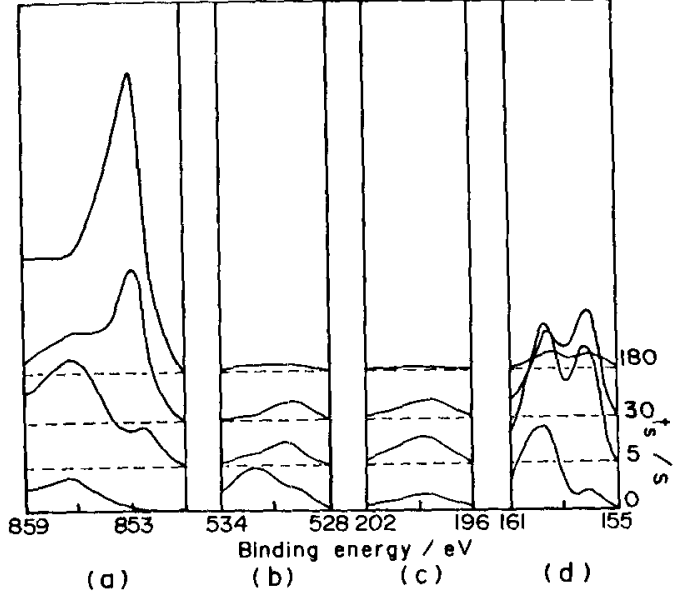

Fig. 4 Depth profiles in XPS of $\mathrm{Ni}\left(2 \mathrm{p}_{3} / 2\right)$ $\begin{array}{llll}\text { (a), } 0\left(1 s_{1} / 2\right) & \text { (b), } \quad \mathrm{Cl}(2 \mathrm{p}) & (\mathrm{c}), \quad \text { and }\end{array}$ $\mathrm{Bi}\left(4 \mathrm{f}_{7 / 2}\right)$ (d) for the nickel electrode pre-treated with $1 \times 10^{-4} \mathrm{M}$ of $\mathrm{BiCl}_{3}$ in $\mathrm{IN}$ $\mathrm{HC} \mathrm{O}_{4}$ for $1 \mathrm{~h}$ at the sputtering time $\mathrm{t}_{\mathrm{s}}$.

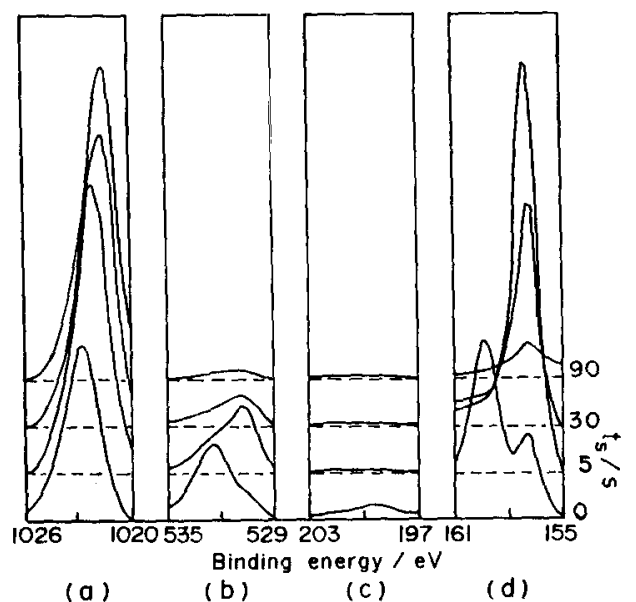

Fig. 5 Depth profiles in XPS of $\mathrm{Zn}\left(2 \mathrm{p}_{3} / 2\right)$ $\begin{array}{llll}\text { (a), } 0\left(1 s_{1 / 2}\right) & \text { (b), } \quad c_{1}(2 p) & \text { (c), and }\end{array}$ $\mathrm{Bi}\left(4 \mathrm{f}_{7,2}\right)$ (d) for the $\mathrm{zinc}$ electrode pretreated with $1 \times 10^{-4} \mathrm{M}$ of $\mathrm{BiCl}_{3}$ in $1 \mathrm{~N} \mathrm{HClO}{ }_{4}$ for $1 \mathrm{~h}$ at the sputtering time $t_{3}$.

ride ion was also present in the film since there was a peak of $\mathrm{Cl}(2 \mathrm{p})$ at 198.7 $\mathrm{eV}$ in the range of $t_{\mathrm{s}}$ between 0 and $30 \mathrm{~s}$. A peak of $B i\left(4 \mathrm{f}_{7 / 2}\right)$ appeared at. $156.6 \mathrm{eV}$, showing the presence of atomic bismuth at the surface and inside of the film.

These spectral observations result in a structural image of the protective film at the nickel surface; the film consists of two layers, an outer layer composed of $\mathrm{Ni}^{2+}, \mathrm{Bi}^{3+}, \mathrm{O}^{2-}$, and $\mathrm{Cl}^{-}$and an inner layer of metallic bismuth. This structure resembles that of the film formed on iron with $\mathrm{BiCl}_{3}$ except for higher contents of $\mathrm{Cl}^{-}$and $\mathrm{Bi}^{3+}$ inside the film on nickel than iron.

Figure 5 shows $X-r a y$ photoelectron spectra of the protective film formed on zinc in $1 \mathrm{~N} \mathrm{HClO}_{4}$ with $\mathrm{BiCl}_{3}$ for $1 \mathrm{~h}$. A peak of $\mathrm{Zn}\left(2 \mathrm{p}_{3 / 2}\right)$ appeared at $1022.7 \mathrm{eV}$, indicating the presence of $\mathrm{Zn}^{2+}$ at the outermost of the film. The binding energy of the peak shifted to $1021.4 \mathrm{eV}$ with an increase in the sputtering time, implying a gradual change of components from $\mathrm{Zn}^{2+}$ to metallic zinc with the depth from the surface. The film seemed to be thinner and the content of metallic bismuth higher than the film formed on nickel. There was $\mathrm{Bi}^{3+}$ only at the surface of the film. Thus, the $f i l m$ on zinc consists of an outer layer composed of $\mathrm{Zn}^{2+}$ and $\mathrm{O}^{2-}$ and an inner layer of metallic bismuth. Protective films formed on the iron, nickel, and zinc surfaces in $1 \mathrm{~N} \mathrm{HClO}_{4}$ with $\mathrm{BiCl}_{3}$ are schematicaliy illustrated in Fig. 6.

\subsection{Formation of protective films on metal} surfaces.

Leidheiser, Jr. ${ }^{6)}$ has suggested a possibility of corrosion inhibition by metallic cations including $\mathrm{Bi}^{3+}$ with the formation of a reduced bismuth layer on the surface of a corroding metal. If the protective film is formed by combination of a cathodic bismuth deposition,

$$
\mathrm{Bi}^{3+}+3 \mathrm{e}^{-} \longrightarrow \mathrm{Bi}
$$

and anodic dissolution of a substrate metal $M$,

$$
M \longrightarrow M^{2+}+2 e^{-}
$$

the facility of these processes should depend on the difference in the equilibrium potential between bismuth and substrate metals. Since the standard electrode potential of bismuth is $0.317 \mathrm{~V}$ vs. $\mathrm{NHE}^{\text {?) }}$, the facility of reactions on metals is in the order, nickel< iron< 


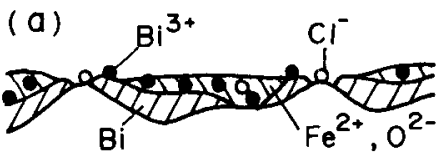

Fe substrate

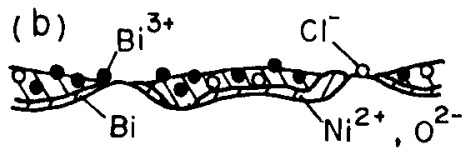

Ni substrate

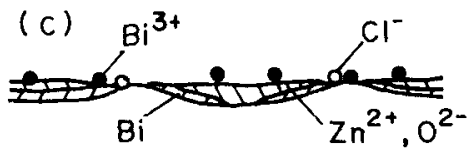

Zn substrate

Fig. 6 Structures of the protective films formed on iron (a), nickel (b), and zinc (c) with $\mathrm{BiCl}_{3}$ in $1 \mathrm{~N} \mathrm{HClO}_{4}$.

zinc. The higher concentration of $\mathrm{Bi}^{3+}$ in the outer layer of the $\mathrm{film}$ on nickel than on iron and zinc may imply incompletion of the film formation on nickel treated with $\mathrm{BiCl}_{3}$ for $1 \mathrm{~h}$. Contrarily, the absence of $\mathrm{Bi}^{3+}$ in the outer layer on zinc is attributed to the complete deposition of bismuth caused by a large electromotive force between $z$ inc and bismuth electrodes.

3.4 Inhibition mechanism of the protective film against metal corrosion.

It has been reported in the previous paper ${ }^{5)}$ that the corrosion potential of an iron electrode inhibited with $\mathrm{BiCl}_{3}$ in acid solutions shifted scarcely from the potential of an uninhibited electrode. Polarization curves shown in Figs. 1 and 2 exhibit little changes of the corrosion potential from the value of uninhibited electrode with an exception of the case for nickel at $1 \times 10^{-4} \mathrm{M}$ of $\mathrm{BiCl}_{3}$. These results suggest that corrosion processes occurring on the metal surface covered with the protective film are cathodic hydrogen evolution reaction and anodic metal dissolution.

As shown in Fig. 6, most of the surface area of the substrate metal is overlaid with the inner layer of metallic bismuth. In order to clarify the corrosion proc- esses on a coupled electrode with a small area of iron to a large area of bismuth in an acid solution, the corrosion potential of the coupled electrode at which the ratio of areas for iron to bismuth is 1 to 500 was measured in $1 \mathrm{~N} \mathrm{HClO}_{4}$. The potential of this electrode, $-0.485 \mathrm{~V}$ vs. SCE was nearly equal to the potential of an iron electrode in $1 \mathrm{~N} \mathrm{HClO}_{4},-0.490 \mathrm{~V}$, indicating no change of the corrosion process on the iron substrate coated with large area of metallic bismuth. The positive shift of the corrosion potential for nickel electrode in the presence of $\mathrm{BiCl}_{3}$ at $1 \times 10^{-4} \mathrm{M}$ may be attributed to the formation of a passive film on the surface of substrate nickel.

Taking the structures of the protective films on metals into consideration, it seems reasonable that the metal dissolution reaction occurs on the surface of substrate metal uncovered with the inner bismuth layer but covered with the outer oxide layer. However, it remains ambiguous whether the hydrogen evolution reaction occurs on the surface of bismuth layer or on the uncovered area of substrate surface. Figure 7 shows polarization curves of bismuth and iron electrodes in $1 \mathrm{~N} \mathrm{HClO}_{4}$ with $\mathrm{BiCl}_{3}$ at $1 \times 10^{-4} \mathrm{M}$. The cathodic current density for the bismuth electrode was remarkably low and constant in the potential region between -0.2 and $-0.65 \mathrm{~V}$. This indicates that bismuth is

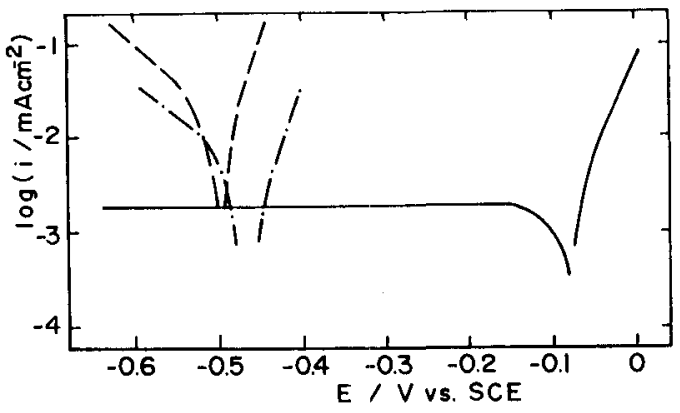

Fig. 7 Polarization curves of bismuth

$(\longrightarrow)$ and iron electrodes in iN $\mathrm{HC} 10_{4}$ with $\mathrm{BiCl}_{3}(--)$ and $\mathrm{BiI}_{3}(-\cdot-)$ at $1 \times 10^{-4} \mathrm{M}$. 


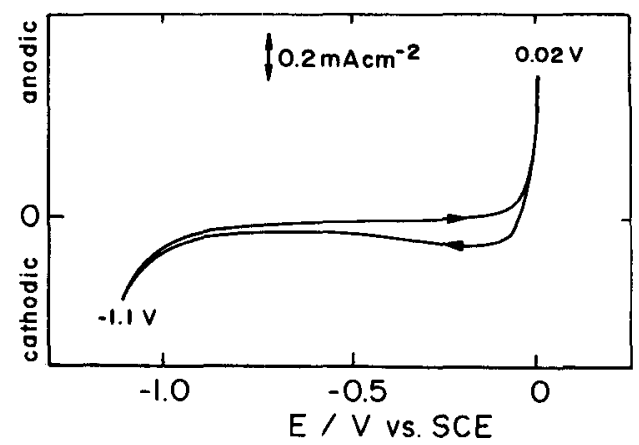

Fig. 8 Cyclic voltammogram for bismuth electrode in $1 \mathrm{~N} \mathrm{HClO}_{4}$ containing $1 \times 10^{-4} \mathrm{M}$ $\mathrm{BiCl}_{3}$ at the sweep rate of $0.1 \mathrm{Vs}^{-1}$.

classified as one of high overpotential metals. Since the current density was markedly low in the potential range corresponding to the Tafel region in the cathodic polarization curve for the iron electrode, the hydrogen evolution reaction must occur at a small area of the surface uncovered with the bismuth metal layer. A cyclic voltammogram for the bismuth electrode in $1 \mathrm{~N} \quad \mathrm{HClO}_{4}$ containing $1 \times 10^{-4} \mathrm{M}$ of $\mathrm{BiCl}_{3}$ showed a drastic increase of the cathodic current for the hydrogen evolution reaction at a more negative potential than about $-1.1 \mathrm{~V}$, as shown in Fig. 8. It is, thus, presumed that the hydrogen evolution reaction can hardly be inhibited by the formation of bismuth layer on the surface of a metal whose corrosion potential in an acid solution is more negative than $-1.1 \mathrm{~V}$.

Since the cathodic current density of the bismuth electrode (Fig. 7) was not markedly lower as compared with that of the uninhibited nickel at the potential in the Tafel region (Fig. 1), $\mathrm{BiCl}_{3}$ in $1 \mathrm{~N}$ $\mathrm{HC} 1 \mathrm{O}_{4}$ cannot suppress the cathodic reaction on nickel to more extents than on iron and zinc, resulting in the lower inhibition efficiency for nickel as shown in Fig. 3. It is thus concluded that the inhibition of the cathodic reaction on the iron, nickel, and zinc electrode covered with the protective film is ascribed to the high hydrogen overpotential of metal-

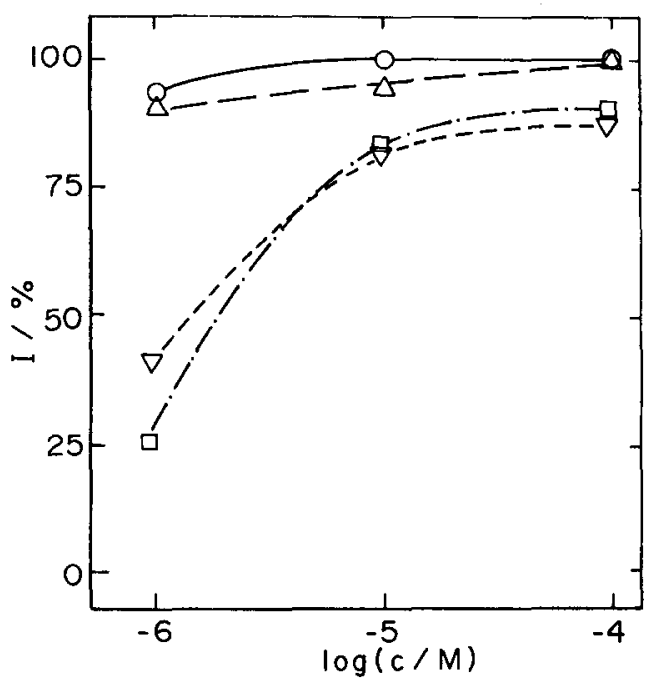

Fig. 9 Inhibition efficiency $\mathrm{I}_{\text {of }} \mathrm{BiI}_{3}$ $(O), \mathrm{BiCl}_{3}(\Delta), \mathrm{Bi}_{2}\left(\mathrm{SO}_{4}\right)_{3}(\square)$, and $\mathrm{Bi}_{2} \mathrm{O}_{3}(\nabla)$ for iron in $1 \mathrm{~N} \mathrm{HClO} \mathrm{O}_{4}$.

lic bismuth deposited on the substrate surface.

Provided that both the anodic and cathodic processes of corrosion reaction occur at the substrate metal surface uncovered with the inner bismuth layer, the corrosion current density can partly be associated with adsorption of an anion on the substrate surface. The specifically adsorbed anion on the iron surface inhibits or stimulates the anodic process of iron corrosion in an acid solution ${ }^{8)}$. Since the adsorbability of anions on the iron surface in $\mathrm{IN} \mathrm{HClO}_{4}$ is closely related to the hard and soft acids and bases principle (HSAB principle) ${ }^{9)}$. inhibition effects of anions on iron corrosion in $1 \mathrm{~N} \mathrm{HClO}_{4}$ decrease in the order ${ }^{10.11)}$, according to the order of softnesses as bases,

$$
\mathrm{I}^{-}>\mathrm{Br}^{-}>\mathrm{Cl}^{-}>\mathrm{SO}_{4}{ }^{2-}>\mathrm{ClO}_{4}^{-} \text {. }
$$

The inhibition efficiencies of $\mathrm{BiI}_{3}$, $\mathrm{BiCl}{ }_{3}, \mathrm{Bi}_{2}\left(\mathrm{SO}_{4}\right)_{3}$, and $\mathrm{Bi}_{2} \mathrm{O}_{3}$ were obtained for iron in $1 \mathrm{~N} \mathrm{HClO}_{4}$ at various concentrations by polarization measurements and are shown in Fig. 9. The order of the inhibition efficiencies was as follows:

$$
\mathrm{BiI}_{3}>\mathrm{BiCl}_{3}>\mathrm{Bi}_{2}\left(\mathrm{SO}_{4}\right)_{3}>\mathrm{Bi}_{2} \mathrm{O}_{3}
$$




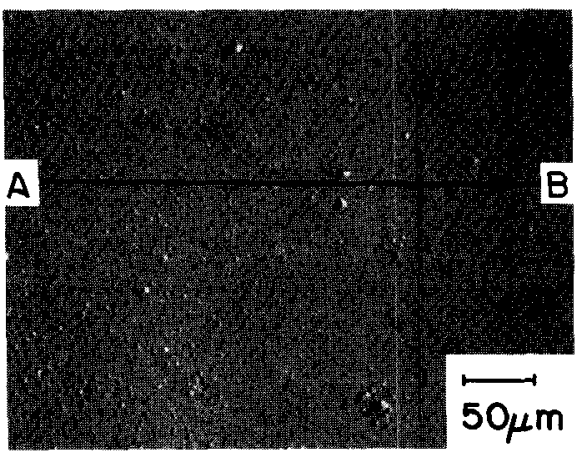

(a)

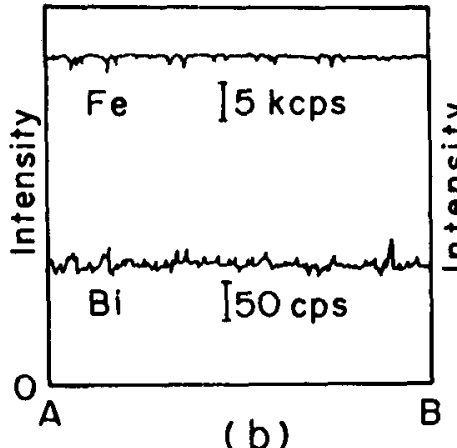

$B$

(b)

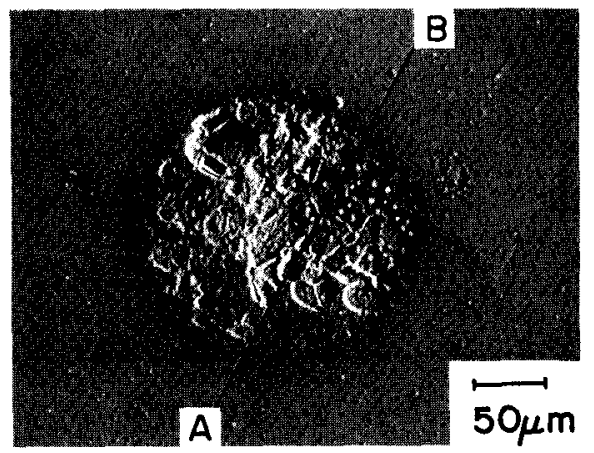

(c)

Fig. 10 SEM photographs of the protective film formed on iron with prior treatment of $\mathrm{BiCl}_{3}$ in $1 \mathrm{~N} \mathrm{HClO}_{4}$ (a and c) and $\mathrm{X}$-ray intensities of $\mathrm{Fe}$, $\mathrm{Bi}$, and Cl with 1 inear scans from $A$ to $B$ ( $b$ and $d$ ).

The adsorbed anion on iron is considered to be $\mathrm{ClO}_{4}^{-}$in a $1 \mathrm{~N} \quad \mathrm{HClO}_{4}$ solution of $\mathrm{Bi}_{2} \mathrm{O}_{3}$. The order of inhibition efficiencies for bismuth compounds agreed with the order of adsorption abilities for inhibitive anions, indicating that the adsorption of anion is closely associated with the inhibition of iron corrosion.

Because this order of anions is basically inapplicable to their adsorption on an oxide but a bulk metal12.13), the inhibition can be attributed to the adsorption on the surface of the iron substrate. In order to investigate the adsorption of anion at an uncovered area of the iron substrate, an electron-probe microanalysis of the iron surface pre-treated with $\mathrm{BiCl}_{3}$ or $\mathrm{Bi}_{2}\left(\mathrm{SO}_{4}\right)_{3}$ in $1 \mathrm{~N} \mathrm{HClO}_{4}$ for $1 \mathrm{~h}$ was carried out after SEM observation.

Figure 10 shows SEM photographs (a and $C)$ and 1 ine analysis of components, Fe, $\mathrm{Bi}$, and $\mathrm{Cl}$ with linear scans from $\mathrm{A}$ to $\mathrm{B}$ in (a) and (c) (b and d) for the protective film afforded by $\mathrm{BiCl}_{3}$ in $\mathrm{IN} \mathrm{HClO}_{4}$. Photograph (a) shows a uniform appearance of the protective film surface. An X-ray spectrum of 1 ine analysis exhibits constant $X$-ray intensities of elements, Fe and $B i$ on the whole area of electrode surface, indicating uniform distribution of elements on the surface. A small spot, which had not been observed in the previous study ${ }^{5}$, was rarely found on the surface, as shown in (c). X-ray intensities of $\mathrm{Fe}, \mathrm{Bi}$, and $\mathrm{Cl}$ with a scan through the spot from A to B in (c) showed a decrease in the content of $\mathrm{Bi}$ and an increase in that of $\mathrm{Cl}$ at the spot, implying an area of the iron surface uncovered with bismuth and adsorption of $\mathrm{Cl}^{-}$. On the other hand, the intensity of $\mathrm{C} 1$ is almost zero at the area where the intensity of $B i$ is high and constant. It is concluded from these results that $\mathrm{Cl}^{-}$is 
not specifically adsorbed on a large area of the deposited bismuth but on a small area of the substrate iron. A SEM photograph of the iron surface pre-treated with $\mathrm{Bi}_{2}\left(\mathrm{SO}_{4}\right)_{3}$ also showed the presence of an area uncovered with bismuth and the $X$-ray intensity of $S$ implied a slight amount of adsorbed sulfate ion at the area, resulting in the lower inhibition efficiency of sulfate than chloride.

Polarization curves of the iron electrode in $1 \mathrm{~N} \mathrm{HClO}_{4}$ with $\mathrm{BiI}$ at $1 \times 10^{-4} \mathrm{M}$ are shown in Fig. 7, indicating that $\mathrm{BiI}_{3}$ suppresses the anodic reaction to a more extent than $\mathrm{BiCl}_{3}$. Consequently, a remarkably high value, $99.7 \%$ of the inhibition efficiency was obtained for iron in $1 \mathrm{~N} \mathrm{HClO}_{4}$ with $\mathrm{BiI}_{3}$ at $1 \times 10^{-4} \mathrm{M}$.

\section{CONCLUSION}

Bismuth (II) chloride is an excellent corrosion inhibitor for iron and zinc in iN $\mathrm{HClO}_{4}$ but that is not the case for nickel. The inhibitor forms a protective film on the surface of a substrate metal; The film consists of two layers, an outer layer comprising $\mathrm{Bi}^{3+}$ and metallic oxide and an inner layer composed of metallic bismuth, except for lacking in inclusion of $\mathrm{Bi}^{3+}$ inside the outer layer on $\mathrm{zinc}$. Corrosion processes of the substrate metal covered with the protective film in acid solutions are the cathodic hydrogen evolution and the anodic metal dissolution reactions on the metal uncovered with the bismuth layer. The inhibition effect of the protective film on metal corrosion is mainly attributed to the coverage of the surface with the bismuth layer of which the hydrogen overpotential is high, to the coverage with the oxide layer and to the anion adsorption on the substrate metal.

\section{REFERENCES}

1) N. Saito, H. Nishihara and K. Aramaki, Corros. Sci., 32, 577 (1991).

2) K. Aramaki, N. Saito and H. Nishihara, Proceedings 7th European Symposium on Corrosion Inhibitors, Vol. 1, Università Degli Studi di Ferrara, Ferrara, p. 29 (1990).

3) N. Saito, H. Nishihara and K. Aramaki, Corros. Sci., in press.

4) M. Ihara, N. Saito, H. Nishihara and K. Aramaki, Corros. Sci., 33, 389 (1992).

5) M. Ihara, H. Nishihara and K. Aramaki, Corros. Sci., in press.

6) H. Leidheiser, Jr., Corrosion, 36, 339 (1980).

7) B. Lovrecek, I. Mekjavić and M. Metikoš-Hukovic, Standard Potentials in Aqueous Solution, (Ed. A. J. Bard, R. Parsons and J. Jordan) Marcel Dekker, New York, p. 180 (1985).

8) K. Aramaki, M. Hagiwara and H. Nishihara, J. Electrochem. Soc., 135, 1364 (1988).

9) R. G. Pearson, Hard and Soft Acids and Bases, Dowden, Hutchinson and Ross, Stroudsberg (1973).

10) K. Aramaki, M. Hagiwara and H. Nishihara, J. Electrochem. Soc., 134, $1896(1987)$.

11) F. H. Walters, J. Chem. Edu., 68, 29 (1991).

12) K. Aramaki, M. Mizoguchi and H. Nishihara, J. Electrochem. Soc., 138, 394 (1991).

13) K. Aramaki and H. Nishihara, Zairyo to Kankyo, 40, 608 (1991). 